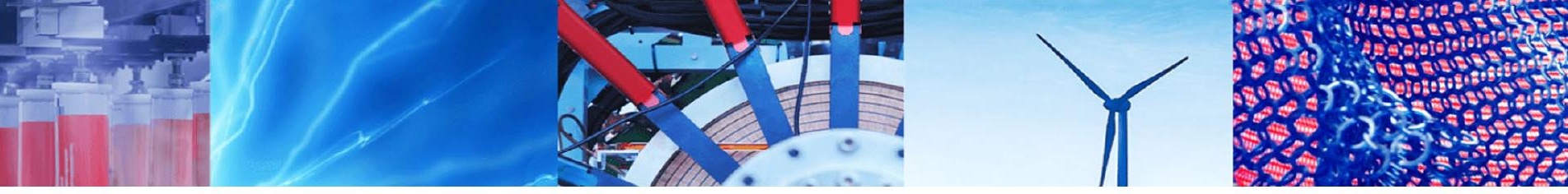

Research Article

\title{
Thermal analysis and artificial vision of laser irradiation on corn
}

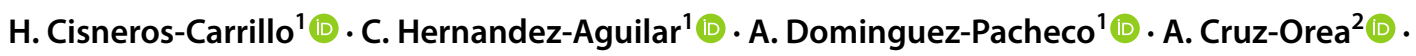 \\ R. Zepeda-Bautista ${ }^{1}$ (D)
}

Received: 4 October 2019 / Accepted: 21 August 2020 / Published online: 31 August 2020

(c) Springer Nature Switzerland AG 2020

\begin{abstract}
Currently evaluation of agricultural product quality is of great importance, in order to guarantee a consumption free of contaminants. In different research areas several techniques are used to evaluate food attributes, related to its quality. Among the techniques used to characterize food stuffs, photothermal techniques have shown versatility to obtain different physical parameters of foods. In the present investigation, the temperature variation effects of different varieties of corn kernels, when excited by laser light during $60 \mathrm{~s}$, were obtained from digital and thermal images, which were analyzed by using artificial vision for characteristic color patterns and geometric measurements to observe the thermal effects, respectively. From these images it was possible to observe variations in temperature, through differences in digital and thermal images of corn samples. Also photoacoustic (PA) spectra were obtained in a wavelength range from 300 to $750 \mathrm{~nm}$, for each variety of corn kernels. Different behaviors of both, image analysis and the PA spectra, showing that one variety of corn kernels present a greater response in both techniques compared to the other varieties. The information obtained could be used in food production areas to identify, classify and determine attributes of grains and seeds of different types of crops.
\end{abstract}

Keywords Corn · Thermal techniques · Photoacoustic spectroscopy · Thermal images · Artificial vision

\section{Introduction}

There is evidence that maize (Zea mays L.) originated in Latin America, especially in Mexico, 7000 years ago [1]. This product is grown in almost all parts of the world due to its nutritional qualities for the generation of animal protein, human consumption and industrial use [1, 2]. In 2017, its global production was 1134.7 million tons, ranking first in the world cereal production, leaving in second and third place wheat and rice, with 771.7 and 769.6 million tons, respectively [3]. In this sense, it is necessary to keep a check and carry out an inspection to guarantee the quality of maize seeds that allows their pollutant-free consumption [4-6]. Normally, these activities are realized by specialists and it takes a long time [5]. So, an automation is necessary in this field to reduce human risks, pollution, pesticides and agrochemicals $[7,8]$.

Quality assessment techniques for agricultural products play an important role in this sector, where they have been shown to provide useful information for analysis. Among the several techniques to characterize different materials, ranging from homogeneous to non-homogeneous ones, the photothermal techniques (PT) stand out because are nondestructive. One of the PT techniques is the photoacoustic spectroscopy (PAS), used to study the optical and reflectance properties in different areas of knowledge, obtaining optical properties in biological materials, having relation to color, quality and state of degradation [9-11]. By using PT techniques, different crops such as wheat, acai, and corn seeds have been studied to obtain various optical and thermal

$\triangle$ A. Dominguez-Pacheco, fartur@hotmail.com | ${ }^{1}$ Posgrado en Ingeniería de Sistemas, Instituto Politécnico Nacional - SEPI - ESIME - Zac., Av. Instituto Politécnico Nacional, s/n, col. Lindavista, Alcaldía Gustavo A. Madero, C. P. 07730 Ciudad de México, México. ${ }^{2}$ Departamento de Física, CINVESTAV-IPN, A. P. 14-740, 07360 Ciudad de México, México. 
properties $[9,10,12,13]$. These techniques may be used as a diagnostic, to obtain features of seeds. Likewise, analysis of thermal images $[7,14]$ has shown that laser irradiation on biological object, such as corn, cause chemical reactions and temperature increment due to its chemical and physical characteristics $[12,15,16]$. So, it is important to know the temperature variations corn grains could experience. In addition, artificial vision systems (AVS) [17] have emerged as alternative evaluation methods for inspection of visual attributes in different industries including agriculture and foods [18].

Images analysis, features extraction, features selection and pattern recognition techniques are used to help AVS [19]. Also, recent researches have demonstrated that patterns recognition technology is efficient technique to classify and identify objects and an important tool to review foods quality [20]. With the different tools generated for the image analysis it has been possible to apply it to perform analysis of grain and seed qualities [18, 19, 21-25], and classification of seeds and fruits [5, 6, 26-29], as well as the segmentation in shrimp structure [20], recognition of patterns in contamination, agricultural plants, livestock and food [4, 8, 30-33]; thus it is also possible to identify diseases in different crops and rice $[22,34]$. By means of several techniques it is possible to determine and characterize agricultural samples to obtain different characteristics that they possess, from the experimental results that techniques generate such as signals, images, data, etc. By means of nuclear magnetic resonance (NMR) technique, in combination with laser light, images were obtained to evaluate mutant pea seeds that showed differences in the embryo fluid [35]. By other hand ultrasound techniques have been applied to evaluate and characterize different fruits, by obtaining their reflection coefficient, in order to determine content of substances such as fructose, sucrose and water [36, 37]. Using NIR infrared hyperspectral imaging system, images were obtained to determine damage to infested and insect-infested bean grains [38]. With PT techniques, that are still in development, as photoacoustic microscopy (PAM), have allowed to observe, by thermal images, the different moisture contents within the seeds, on the other hand by using photopyroelectric microscopy (PPEM), it was possible to obtain images of different types of corn seeds and also statistical analysis models to determine the differences in their structures and pigmentations $[39,40]$ also other PT techniques have been used to study physical and chemical properties in different food products.

The aim of this research was to analyze the optical absorption coefficient, thermal effects of laser irradiation and get characteristic patterns of color and geometrical measurements using machine vision for crystalline, floury and hybrid corn grains.

\section{Materials and methods}

\subsection{Biological material}

In the present investigation, three varieties of corn grains were studied: crystalline, mealy and $\mathrm{H} 70$ hybrid grown in the spring-summer 2017 cycle in San Marcos, in state of Guerrero and Montecillo, Texcoco in state of Mexico, Mexico. The samples were randomly selected from $1 \mathrm{~kg}$ of each variety. The physical dimensions were measured with a vernier instrument and their average values are shown in Table 1.

\subsection{Experimental setup for PAS, thermal images and AVS}

PAS experimental setup is shown in Fig. 1; this setup consists of a Xenon lamp (Research Arc Lamp Source, Oriel) at $700 \mathrm{~W}$ power, as light source, a monochromator (Oriel) to obtain a monochromatic light beam, and also to scan the wavelength, from the light source. A mechanical

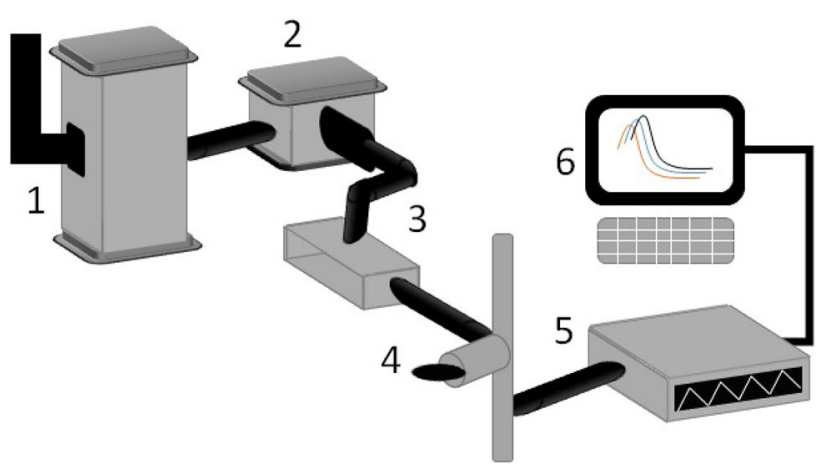

Fig. 1 Experimental setup for PAS according to [9]. 1 Xenon lamp, 2 monochromator, 3 Chopper, 4 photoacoustic cell, 5 lock-in amplifier, and 6 PC
Table 1 Physical parameters values comparison of sample studied

\begin{tabular}{llllll}
\hline Variety & Productive cycle & Color & Length $(\mathrm{mm})$ & Width $(\mathrm{mm})$ & Thickness $(\mathrm{mm})$ \\
\hline Crystalline & 2017 & Yellow & $13.11 \pm 0.92$ & $11.21 \pm 0.35$ & $4.97 \pm 0.79$ \\
Floury & 2017 & Pink & $13.39 \pm 1.75$ & $12.97 \pm 1.10$ & $5.49 \pm 0.65$ \\
H70 Hybrid & 2017 & Yellow & $12.73 \pm 0.65$ & $8.33 \pm 0.58$ & $4.40 \pm 0.36$ \\
\hline
\end{tabular}


optical chopper is used to modulate the monochromatic light beam, at $17 \mathrm{~Hz}$ fixed frequency, and also an optical fiber was used to guide the modulated light beam on the sample, which is inside of the PA cell, hermetically sealed with two quartz crystals and silicone grease. Inside the PA cell the modulated light is absorbed by the sample and transformed into modulated heat, which diffuses to the air in contact with the sample, then temperature variations occur in this gas, which provokes modulated gas expansions and finally pressure variations inside the PA cell. These gas pressure changes are detected by an electret microphone, generating an electrical signal, amplified by a lock-in amplifier (SR-850), and then generating the PA signal, which was sent to a personal computer, where the data were acquired and recorded. PA spectra were obtained as a function of the incident light wavelength, ranging from 320 to $700 \mathrm{~nm}$. The corn kernels were cut to fit the PA cell dimensions, $6 \mathrm{~mm}$ diameter and $3 \mathrm{~mm}$ thickness, also the corn kernels were random form selected to obtain the PA spectra.

The instrumentation used to obtain the thermal images was performed by using an IR camera (i 5 model; $6.8 \mathrm{~mm}$ lens; accuracy of $\pm 2 \%$; thermal sensitivity $<0.1$ at $25^{\circ} \mathrm{C}$; $140 \times 140$ of thermal images resolution and temperature range -20 to $250{ }^{\circ} \mathrm{C}$; FLIR Systems Wilsonville, OR, USA), and as excitation source was used a diode laser at $650 \mathrm{~nm}$ wavelength, $27 \mathrm{~mW}$ power (Tyson Technology Co.) instrumentation is controlled by a digital timer. The samples were placed in a silicone net lying in an empty space on a plastic container (Fig. 2).

Twenty-five images were obtained for each grain and variety, providing a total of 300 thermal images. These images were the result of the capture process with iterations, when the samples were excited and de-excited,

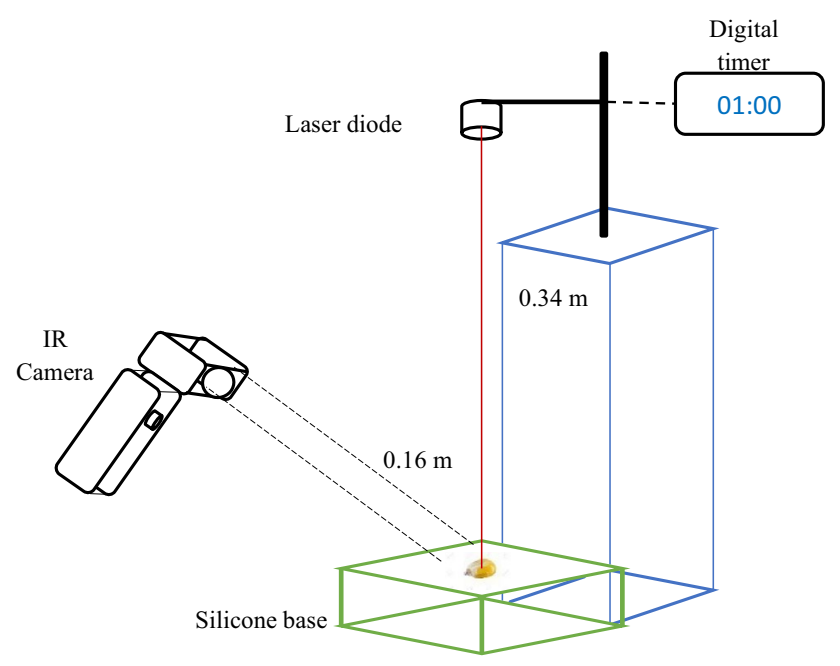

Fig. 2 Experimental setup thermal analysis according to [7] where evolution and thermal decay could be observed. Twelve thermal images were obtained during laser irradiation and without irradiation during $60 \mathrm{~s}$, every $5 \mathrm{~s}$. The corn kernels were placed on a fixed net on the opposite side to the embryo, the net is suspended in the air only holding each of its corners, and the net is made up of very fine silicone threads. The distance between the laser and the camera to the sample was $0.34 \mathrm{~m}$ and $0.16 \mathrm{~m}$, respectively. The images were observed with FLIR Tools (V6.4) software to obtain the temperature value at the point where the laser impinges on the corn. The experiment was carried out at $23 \pm 1{ }^{\circ} \mathrm{C}$ temperature and $65 \pm 2 \%$ humidity. The temperature and humidity parameters were kept constant with the indicated values above, because the experimental setup was inside a container with thermal insulation.

Data capture, preprocessing and feature extraction were including in AVS. An HP Scanjet G4050 (1200 dpi resolution) was used in data capture. Digital images were preprocessed (converted to gray levels, black and white, edge detection, dilation, filling, delete border edges and objects of smaller size) by using Matlab R2014b software. Feature extraction is based on geometric measurements (axis: major, minor and area) and color using the CBIR technique [41]. Basically, the CBIR technique generates a characteristic vector by calculating the averages of the image, where the three-color planes (red, green and blue) are firstly separated. After that, for each plane the mean color of a row and column is calculated, the average of all the mean colors of rows and columns for each plane is calculated. Finally, the characteristics of the three planes are combined to form a characteristic vector.

\subsection{Statistics analysis}

Data were subjected to variance analysis using the SAS GLM procedures (SAS, V9). The least significant difference test (LSD) at the $5 \%$ probability level was used for comparing treatments [42].

\section{Results and discussion}

The obtained PA spectra, for the studied corn kernel varieties, are shown in Fig. 3. From these spectra it is possible to observe that the PA signal is higher for $\mathrm{H}-70$ hybrid corn kernel with respect to the other two varieties in the wavelength range from 300 to $375 \mathrm{~nm}$. The absorption band, with a shoulder around $375 \mathrm{~nm}$, has a greater absorption because this type of samples have different natural pigments, some of these are different flavonoids, so for each variety of corn kernels the PA signal shows differences because they have different natural pigments. The PA signal after the shoulder at $375 \mathrm{~nm}$ decays, for the three 


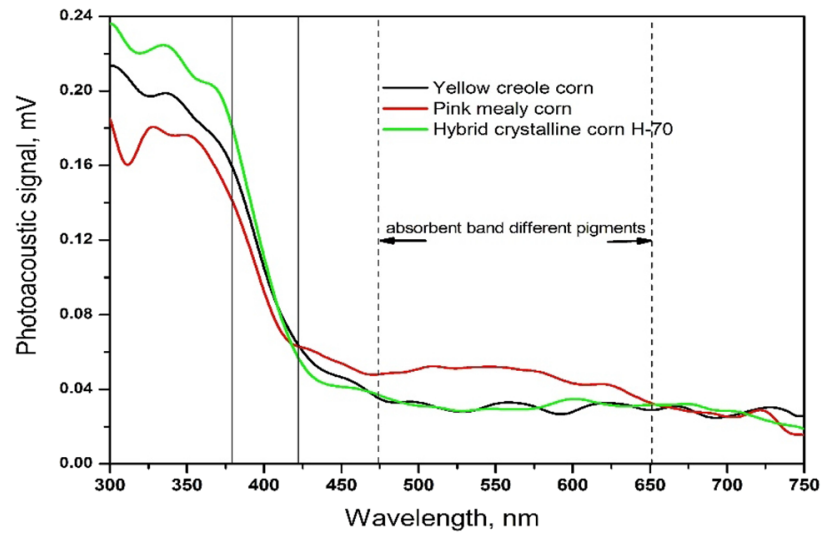

Fig. 3 Optical absorption spectra for three varieties corn grain

varieties of corn kernels, also at $425 \mathrm{~nm}$ wavelength it is possible to observe changes in the PA signal, depending of the corn kernel PA spectrum. The corn kernel with floury structure shows a wide optical absorption band, from 425 to $650 \mathrm{~nm}$ wavelength. This behavior could be related to the pink pigmentation of its surface layer (pericarp). Also it has been reported an absorbent band in corn seeds, in a wavelength range from 445 to $610 \mathrm{~nm}$, this absorption would be mainly due to the dye of a fungicide applied in these seeds, which is reddish in color [43]. These results show that PAS technique is an indirect measure of sample pigmentation [44].

Mean temperature comparison of the three varieties: 1-crystalline, 2-floury and 3-hybrid, is shown in Table 2. The temperature of the varieties showed statistically significant differences from $t_{1}$ to $t_{12}$ during laser light exposure $(p \leq 0.05)$ where pink floury corn grain had the highest variation in $t_{12}\left(27.07^{\circ} \mathrm{C}\right)$ with respect to its initial temperature $t_{0}\left(23.4^{\circ} \mathrm{C}\right)$, having an increment of $13.6 \%$ $\left(3.67^{\circ} \mathrm{C}\right.$ ) and a $0.31^{\circ} \mathrm{C}$ average increase. $\mathrm{H}-70$ Hybrid corn grain had the lowest temperature increase in $t_{12}\left(24.35^{\circ} \mathrm{C}\right)$ with respect to its initial temperature $t_{0}\left(23.4^{\circ} \mathrm{C}\right)$, having an increase of $3.9 \%\left(0.95^{\circ} \mathrm{C}\right)$ and a $0.08{ }^{\circ} \mathrm{C}$ average gain. On the other hand, the result showed statistically significant differences from $t_{0}$ to $t_{3}$ in temperature diminution period (laser light off) where floury corn grain had the highest decrement in $t_{12}\left(23.9^{\circ} \mathrm{C}\right)$ with respect to its initial temperature $t_{0}\left(27.07^{\circ} \mathrm{C}\right)$, having a variation of $11.73 \%\left(3.17^{\circ} \mathrm{C}\right)$ and a $0.26^{\circ} \mathrm{C}$ average decay. Yellow crystalline corn grain had the lowest temperature diminution in $t_{12}\left(24.15^{\circ} \mathrm{C}\right)$ with respect to its initial temperature $t_{0}\left(24.80^{\circ} \mathrm{C}\right)$, having a variation of $2.62 \%\left(0.65^{\circ} \mathrm{C}\right)$ and a $0.05^{\circ} \mathrm{C}$ average decay. Fig. 4 shows floury corn grain had the highest temperature variation in $5 \mathrm{~s}$ both, increase and diminution.

Figure 5 shows the thermal images of corn varieties used on this experiment. There are eight columns where the first refers to the images without exposure laser light

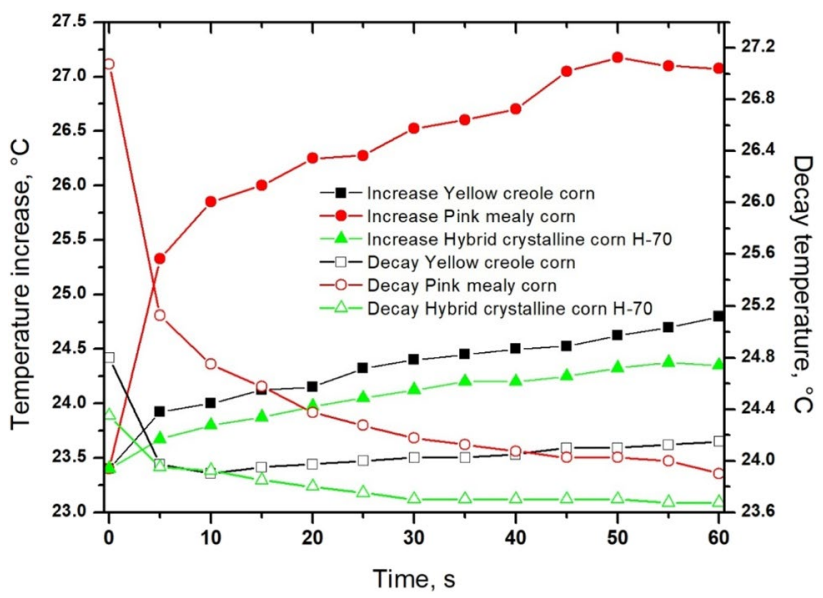

Fig. 4 Evolution and decay of temperature. CCA crystalline, CHR floury and $\mathrm{H} 7 \mathrm{O}$ Hybrid

at time $t_{0}$, from column two to four the temperature during the exposure laser light is shown, from column five to eight the temperature decay is shown.

Thermal behavior could be related with the inner structure and color as it has been find by other researcher who has reported the crystalline and floury type maize seeds dyed with a dark color absorb more head when they are exposed to irradiation of laser light in a given time and minor heat when they were in their natural color $[7,44]$.

Figure 6 shows the obtained images in the preprocessing stage of the AVS: (a) original image, (b) gray levels, (c) black and white, (d) edge detection, (e) dilation, (f) filling, (g) delete border edges and ( $h$ ) delete smaller size objects. A circularity level and an area equal to or greater than $40 \%$ and 500 pixels, respectively, were used to get the interest object (Fig. 6h). The features were extracted from this image.

Table 3 shows the comparison of mean values of characteristics obtained by AVS: (a) color features in red, green and blue (RGB) space using CBIR technique and (b) geometrical features (major, minor axis and area) to optical and thermal images. Optical images has the following results: yellow-crystalline and pink-floury corn grains has the highest variation in red and blue color feature value with 142.195 and 145.9181 , respectively, the values to green channel has differences in the three varieties; pinkfloury corn grain has the highest variation in major, minor axis and area with $373.34,307.26$ and 89,501 pixels, respectively. Thermal images values has the following results: yellow-crystalline and $\mathrm{H}-70$ hybrid corn grains has the highest variation in Green and Blue color feature with 112.56 and 46.26 , respectively, the values to red channel has differences in the three varieties; pink-floury corn grain has the highest variation in mayor, minor axis and area with 33.02, 29.04 and 714 pixels, respectively. 


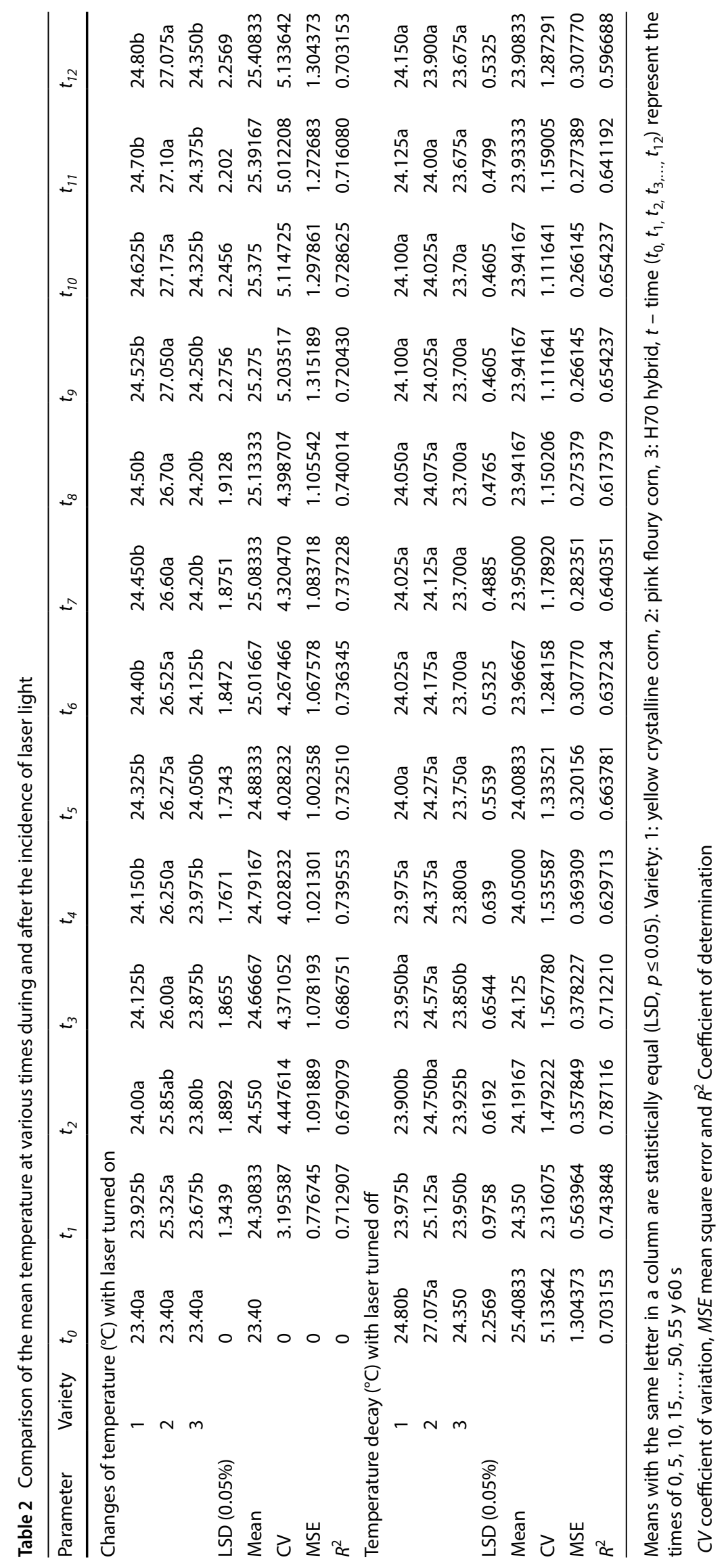


Fig. 5 Optical and thermal images (evolution and temperature decay). a Crystalline, b floury and c $\mathrm{H} 70$ hybrid
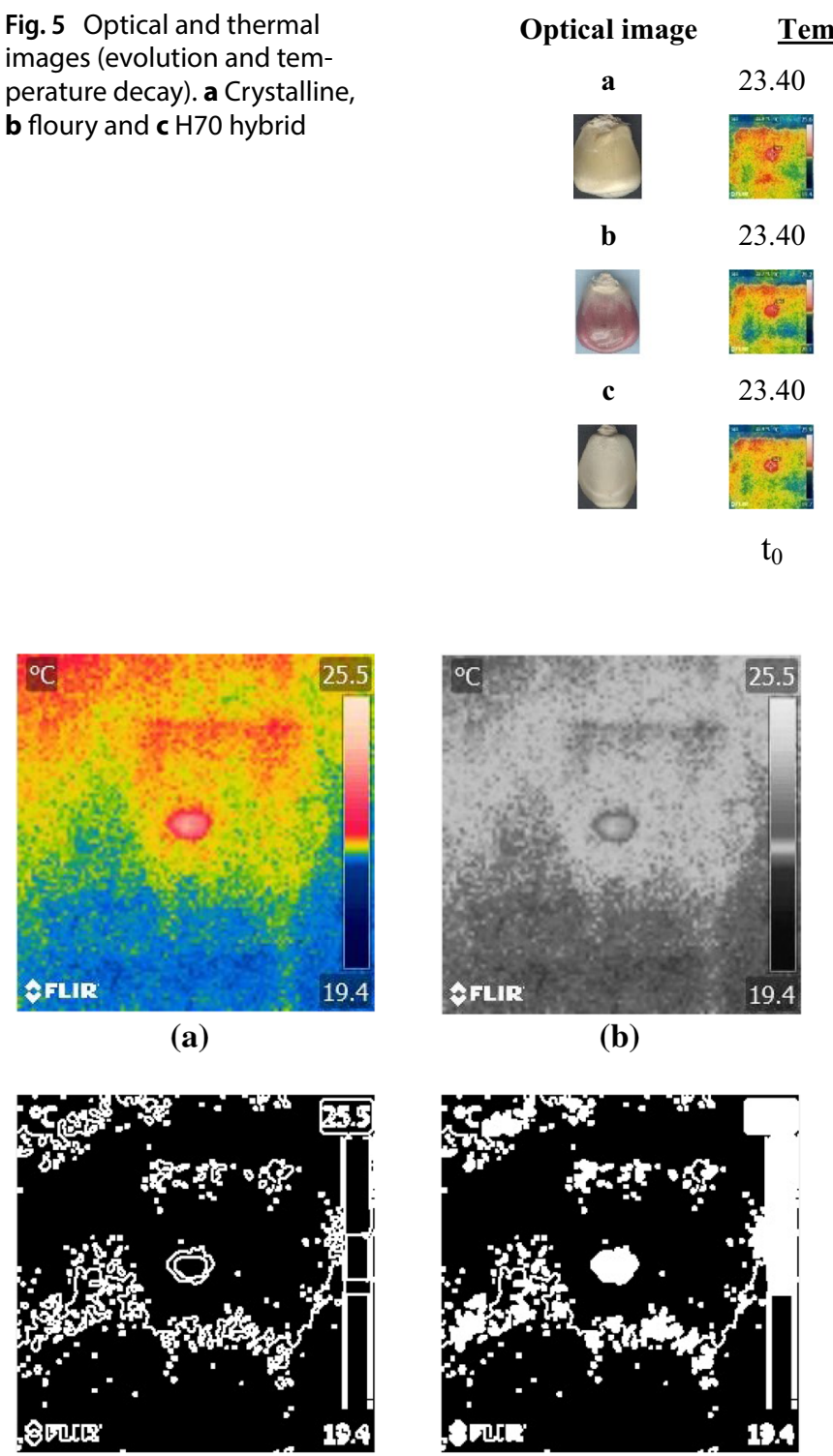

(e) (b)

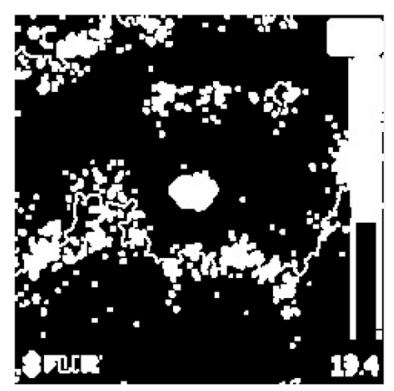

(f)

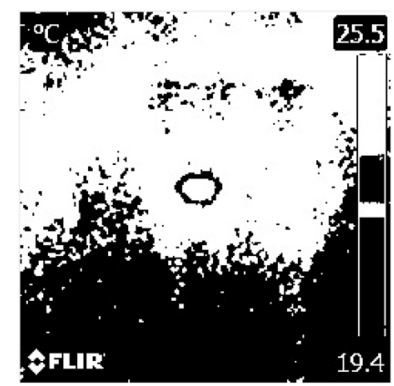

(c)

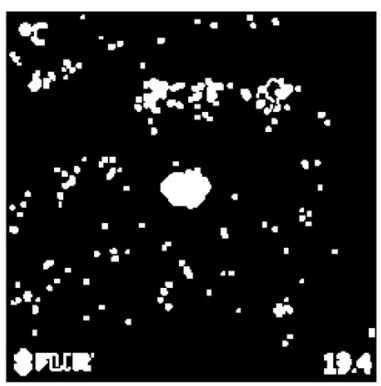

(g)
Temperature decay $\left({ }^{\circ} \mathrm{C}\right)$

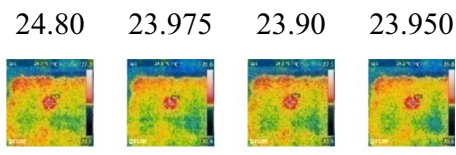

$27.075 \quad 25.125 \quad 24.750 \quad 24.575$

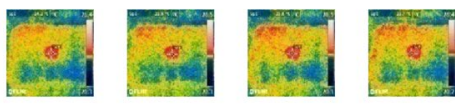

$\begin{array}{llll}24.350 & 23.950 & 23.925 & 23.850\end{array}$

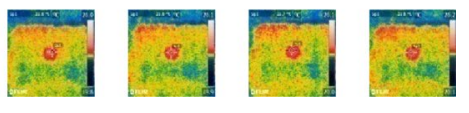

$\begin{array}{llll}t_{0} & t_{1} & t_{2} & t_{3}\end{array}$

Fig. 6 Thermal images preprocessing. a Original image, $\mathbf{b}$ gray levels, $\mathbf{c}$ black and white, $\mathbf{d}$ edge detection, e dilation, $\mathbf{f}$ filling, $\mathbf{g}$ delete border edges and $\mathbf{h}$ delete smaller size objects

Table 3 Comparison of mean values of characteristics obtained by AVS

\begin{tabular}{|c|c|c|c|c|c|c|}
\hline \multirow[t]{2}{*}{ Variety } & \multicolumn{3}{|c|}{ Color features } & \multicolumn{3}{|c|}{ Geometrical features (pixels) } \\
\hline & $\mathrm{R}$ & G & B & Major axis & Minor axis & Area \\
\hline \multicolumn{7}{|c|}{ Optical images values } \\
\hline 1 & 155.49 & 145.64 & 120.52 & 322.49 & 252.39 & 62,745 \\
\hline 2 & 153.60 & 141.67 & 145.92 & 373.34 & 307.26 & 89,501 \\
\hline 3 & 142.20 & 137.51 & 124.59 & 265.37 & 201.98 & 4165 \\
\hline \multicolumn{7}{|c|}{ Thermal images values } \\
\hline 1 & 239.24 & 112.56 & 56.86 & 32.40 & 26.87 & 668 \\
\hline 2 & 245.89 & 120.89 & 55.27 & 33.02 & 29.04 & 714 \\
\hline 3 & 244.84 & 125.42 & 46.26 & 29.62 & 27.35 & 576 \\
\hline
\end{tabular}

Variety: 1 Yellow crystalline, 2 pink floury, 3 yellow $\mathrm{H} 70$ hybrid

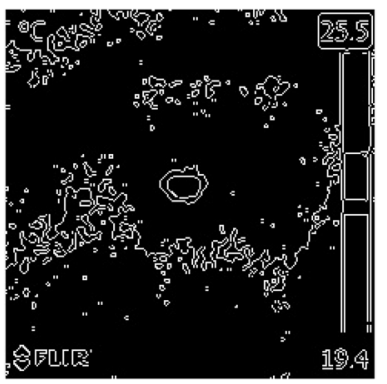

(d)

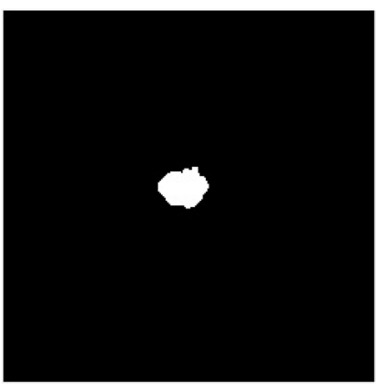

(h) 


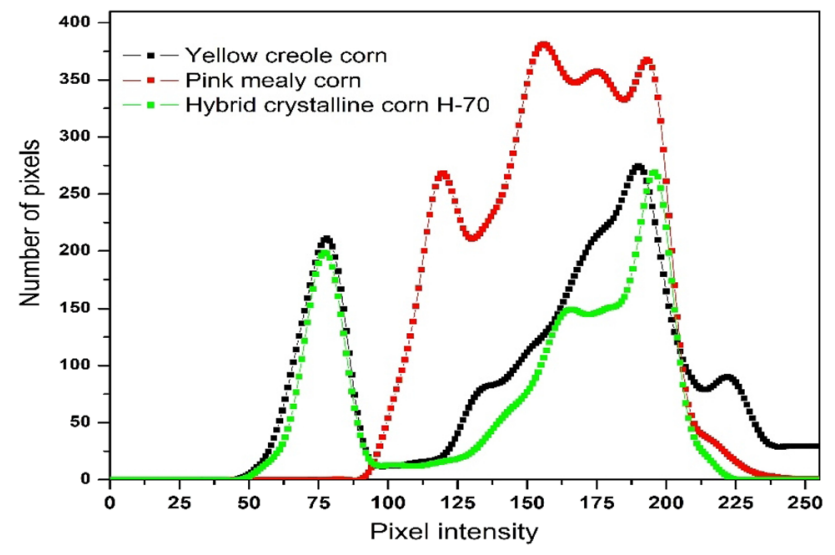

Fig. 7 Gray level histogram for digital images

The optical images histogram (grays scale) of the three varieties corn grain is shown in Fig. 7. Pink floury corn grain has the highest number of pixels on 87.5-212.5 intensity level with respect to the others corn grains (yellow crystalline type). This behavior was similar when a graph was made to RGB color channels to each variety. These results coincide with the optical absorption spectra (Fig. 3) and thermal analysis (Fig. 4) where pink floury corn grain has the highest variation in signal and temperature, respectively, and could be related with the pericarp's pigmentation and inner structure (floury or crystalline type).

\section{Conclusions}

In this research, physical characteristics of the varieties studied showed statistically significant differences in their parameters.

The incidence of laser light during $60 \mathrm{~s}$ affects thermally corn grains variety used and these changes can be measured through a thermal camera. Pink floury corn grain had the greatest variation in temperature with respect to the initial temperature when they were exposed to laser light irradiation and crystalline corn grains decreased its temperature more rapidly.

Optical absorption spectra for pink floury corn grain had a different behavior wavelength $445-610 \mathrm{~nm}$ range with respect to the others varieties (crystalline type) that had a similar behavior. Pink floury corn grain had the highest variation on gray levels and RGB histogram when they were analyzed with AVS. Also, color and geometrical measurements showed significant differences in their parameters for optical and thermal images. Pink floury corn grain had the highest variation when methods results were compared. This behavior could be related with the pericarp's pink pigmentation and floury structure of this grain.
AVS could be an alternative method to identify crystalline and floury corn grains using an optimal features vector with color and geometrical measurements. Thermal analysis, photoacoustic spectroscopy and artificial vision system could be useful strategies to identify and classify corn grains.

Acknowledgements The authors would like to thank the Instituto Politécnico Nacional, through the CONACYT, COFAA, EDI and projects SIP scholarships. The support Research and Postgraduate Secretariat (Project SIP 20196252), Hermenegildo Cisneros Carrillo thank for the support, for PhD studies, through the grant awarded by Conacyt and also, Photothermal Techniques Laboratory of Physics Department, CINVESTAV-IPN for the support to develop the experiments of the present study. We also thank Ing. Esther Ayala for her technical support at the Physics Department, CINVESTAV-IPN.

\section{Compliance with ethical standards}

Conflict of interest On behalf of all authors, the corresponding author states that there is no conflict of interest.

\section{References}

1. Benitez-Rodriguez MG, Zepeda-Bautista R, Hernandez-Aguilar C, Virgen-Vargas J, Rojas-Martinez I, Dominguez-Pacheco A (2014) Physical characteristics and yield of maize grain in rainfed conditions of high valleys of mexico. Acta Agroph 21:403-414

2. Tolera A, Sundstol F, Said AN (1998) The effect of stage of maturity on yield and quality of maize grain and stover. Anim Feed Sci Tech 75:157-168

3. Food and Agriculture Organization (2019) https://www.fao.org/ faostat/en/\#data/QC.

4. Hong-Ju H, Da-Wen S (2015) Hyperspectral imaging technology for rapid detection of various microbial contaminants in agricultural and food products. Trends Food Sci Tech 46:99-109

5. Pandey N, Krishna S, Sharma S (2013) Application of hyperspectral imaging to discriminate the variety of maize seeds. IJCATR 9:225-234

6. Wang L, Da-Wen S, Pu H, Zhu Z (2016) Application of hyperspectral imaging to discriminate the variety of maize seeds. Food Anal Methods 9:225-234

7. Hernandez-Aguilar C, Dominguez-Pacheco A, Cruz-Orea A (2015) Thermal changes of maize seed by laser irradiation. Int J Thermophys 36:2401-2409

8. Guijarro M, Riomoros I, Pajares G, Zitinski P (2015) Discrete wavelets transform for improving greenness image segmentation in agricultural images. Comput Electron Agr 118:396-407

9. Hernandez-Aguilar C, Cruz-Orea A, Ivanov R, DominguezPacheco A, Carballo A, Moreno I, Rico R (2011) The optical absorption coefficient of maize seeds investigated by photoacoustic spectroscopy. Food Biophys 6:481

10. Rosencwaig A, Gersho A (1976) Theory of the photoacoustic effect with solids. J Appl Phys 47:64-69

11. Lomeli-Mejia PA, Urriolagoitia G, Jimenez-Perez JL, Cruz-Orea A, Lecona-Butron $\mathrm{H}$, Villegas-Castrejon $\mathrm{H}$ (2005) Photoacoustic and SEM analysis of fracture bone callus to different consolidation times. J Phys 125:733-735

12. Hernandez-Aguilar C, Dominguez-Pacheco A, Cruz-Orea A, Ivanov-Tsonchev R (2015) Thermal effects of laser irradiation on maize seeds. Int Agrophys 29:147-156 
13. Rezende DV, Nunes OAC, Oliveira AC (2009) Photoacoustic Study of Fungal Disease of Acai (Euterpe oleracea) Seeds. Int J Thermophys 30:1616-1625

14. Dominguez-Pacheco $A$, Hernandez-Aguilar $C$, Zepeda-Bautista R, Martinez-Ortiz E (2012) Análisis térmico de semilla de maíz con plaga por microscopía fotopiroeléctrica. SMCSYV 25:92-96

15. Popov AY, Popova NA, Tyurin AV (2007) A physical model of the action of low-intensity laser radiation on biological objects. Opt Spectrosc 103:671-677

16. Ferdosizadeh L, Sadat-Noori SA, Zare N, Saghafi S (2013) Assessment of diode laser pretreatments on germination and yield of wheat (Triticum aestivum L.) under Salinity Stress. World J Agric Res 1:5-9

17. Velez-Serrano JF, Moreno-Diaz AB, Sanchez-Calle A, SanchezMarin JLE (2003) Vision por computador. In: Introducción a la visión artificial, 2nd edn. DYKINSON, pp 1-19

18. Vithu P, Moses JA (2016) Machine vision system for food grain quality evaluation. JA Trends Food Sci Tech 56:13-20

19. Mahajan S, Das A, Sardana HK (2015) Image acquisition techniques for assessment of legume quality. Trends Food Sci Tech 42:116-133

20. Liu Z, Cheng F, Zhang W (2016) A novel segmentation algorithm for clustered flexional agricultural products based on image analysis. Comput Electron Agr 126:44-54

21. Yang L, Wang Z, Gao L, Bai X (2017) Detection of maize kernels breakage rate based on K-means clustering. AIP Conf Proc 1834:030025

22. Erdem-Ozcelik A, Nisanci R (2016) Land use patterns for driving environmental management of tea agricultural croplands. Comput Electron Agr 122:41-54

23. Aboonajmi M, Faridi $\mathrm{H}$ (2016) Nondestructive quality assessment of Agrofood products. IRNDT A13105

24. Leyva-Ovalle OR, Carballo-Carballo A, Mejía-Contreras JA, Vazquez-Carrillo MG (2002) Procesamiento digital de imágenes para la estimación de textura de endospermo en líneas de maíz. Rev Fitotec Mex 25:355-365

25. Granitto PM, Verdes PF, Alejandro-Ceccatto H (2005) Large-scale investigation of weed seed identification by machine visión. Comput Electron Agr 47:15-24

26. Cardenas-Perez S, Chanona-Perez J, Mendez-Mendez JV, Calderon-Dominguez G, Lopez-Santiago R, Perea-Flores MJ, ArzateVazquez I (2017) Evaluation of the ripening stages of apple (Golden Delicious) by means of computer vision system. Biosyst Eng 159:46-58

27. Figueredo-Avila GA (2016) Clasificación de la manzana royal gala usando visión artificial y redes neuronales artificiales. Res Comput Sci 114:23-32

28. Yongting T, Jun Z (2017) Automatic apple recognition based on the fusion of color and 3D feature for robotic fruit picking. Comput Electron Agr 142:388-396

29. Kurtulmus F, Alibas I, Kavdir I (2016) Classification of pepper seeds using machine vision based on neural network. Int J Agric Biol Eng 9:51-62

30. Grinblat GL, Uzal LC, Larese MG, Granitto PM (2016) Deep learning for plant identification using vein morphological patterns. Comput Electron Agr 127:418-424
31. Hernandez-Hernandez JL, Garcia-Mateos G, Gonzalez-Esquiva JM, Escarabajal-Henarejos D, Ruiz-Canales M-M (2016) Optimal color space selection method for plant/soil segmentation in agricultura. Comput Electron Agr 122:124-132

32. Kumar S, Pandey A, Ram-Satwik KS, Kumar S, Kumar-Singh S, Kumar-Singh A, Mohan A (2018) Deep learning framework for recognition of cattle using muzzle point image pattern. Measurement 116:1-17

33. Leiva-Valenzuela GA, Mariotti M, Mondragon G, Pedreschi F (2018) Statistical pattern recognition classification with computer vision images for assessing the furan content of fried dough pieces. Food Chem 39:718-725

34. Lu Y, Yi S, Zeng N, Liu Y, Zhang Y (2017) Identification of rice diseases using deep convolutional neural networks. Neurocomputing 267:378-384

35. Melkus G, Rolletschek H, Radchuk R, Fuchs J, Rutten T, Wobus U, Altmann T, Jakob P, Borisjuk L (2009) The metabolic role of the legume endosperm: a noninvasive imaging study. Plant Physiol 151:1139-1154

36. Morrison DS, Abeyratne UR (2014) Ultrasonic technique for non-destructive quality evaluation of oranges. J Food Eng 141:107-112

37. Valente M, Prades A, Laux D (2013) Potential use of physical measurements including ultrasound for a better mango fruit quality characterization. J Food Eng 116:57-64

38. Kaliramesh S, Chelladurai V, Jayas DS, Alagusundaram K, White NDG, Fields PG (2013) Detection of infestation by Callosobruchus maculatus in mung bean using near-infrared hyperspectral imaging. J Stored Prod Res 52:107-111

39. Dominguez-Pacheco A, Hernandez-Aguilar C, Cruz-Orea A, Martinez-Ortiz E, Ayala-Maycotte E (2010) Characterization of seeds with different moisture content by photoacoustic microscopy. J Phys 214:012060

40. Rojas-Lima JE, Dominguez-Pacheco A, Hernandez-Aguilar C, Cruz-Orea A (2016) Statistical analysis of photopyroelectric signals using histogram and kernel density estimation for differentiation of maize seeds. Int J Thermophys 37:98

41. Kekre HB, Mishra D, Narula S, Shah V (2011) Color feature extraction for cbir. Int J Eng Sci Technol 3:8357-8365

42. Hines WW, Montgomery DC (1996) Probabilidad y estadística para ingeniería y administración, 3rdra edn. S.A de C.V, Compañía editorial continental, p 380

43. Dominguez-Pacheco A, Hernandez-Aguilar C, Cruz-Orea A, Briseño-Tepepa BR, Sanchez-Sinencio F, Martinez-Ortiz E, Valcarcel JP (2009) Evaluation of wheat and maize seeds by photoacoustic microscopy. Int J Thermophys 30:2036

44. Bicanic D, Vrbic I, Cozijnsen J, Lemic S, Doka O (2006) Sensing the heat of tomato products red: the new approach to the objective assessment of their color. Food Biophys 1:14-20

Publisher's Note Springer Nature remains neutral with regard to jurisdictional claims in published maps and institutional affiliations. 